\title{
Cervical Extradural Arteriovenous Fistula without Intradural Drainage Successfully Treated with Endovascular Treatment Using Both Transvenous and Transarterial Approach: Case Report and Review of Literatures
}

\author{
Toshiyuki OKAZAKI, ${ }^{1}$ Yukoh OHARA, ${ }^{1,2}$ Hidenori MATSUOKA, ${ }^{1}$ Kazuaki SHIMOJI, ${ }^{2}$ \\ Kazunari KOGURE, ${ }^{1}$ Nahoko KIKUCHI, ${ }^{1}$ Takaoki KIMURA, ${ }^{1}$ Shintaro NAKAJIMA, ${ }^{2}$ \\ Satoshi TANI, ${ }^{1}$ Junichi MIZUNO, ${ }^{1}$ Hajime ARAI, ${ }^{2}$ and Hidenori OISHI ${ }^{2}$ \\ ${ }^{1}$ Center for Minimally Invasive Spinal Surgery, Shin-yurigaoka General Hospital, \\ Kawasaki, Kanagawa, Japan \\ ${ }^{2}$ Department of Neurosurgery, Juntendo University Faculty of Medicine, Tokyo, Japan
}

\begin{abstract}
The classification of spinal extradural arteriovenous fistulas (AVFs) was reported based on a case series treated by microsurgery in 2009 and endovascular interventions in 2011. The present report describes a patient with extradural AVFs at the cervical spine manifesting gradual progressive radiculomyelopathy of bilateral upper extremities. Magnetic resonance imaging (MRI) revealed a mass sign from $\mathrm{C} 1$ to $\mathrm{C} 4$ at the right ventral side and the spinal cord was deviated to the left and indicated as a flow void sign. Diagnostic angiography revealed an extradural AVFs located at the C1-C4 level that was supplied by bilateral radicular artery from the vertebral artery (VA) and right ascending cervical artery (ACA). The shunting points were recognized multiply at C2/3 and C3/4 levels on the right. The transvenous embolization to the enlarged extradural venous plexus around the shunting points via right hypoglossal canal and the transarterial embolization against multi-feeders of the branch of left radicular artery, right ACA achieved complete occlusion of the lesions. His symptom was gradually recovered, and angiography performed 2 weeks after embolization showed no recurrence. When the arteriovenous shunts in the upper cervical spine were high flow shunts, transvenous approach via the hypoglossal canal might be one option for the treatment of spinal extradural AVFs.
\end{abstract}

Keywords: extradural arteriovenous fistula, cervical spine, endovascular treatment, anterior condylar emissary vein

\section{Introduction}

Spinal arteriovenous malformations (AVMs) including spinal arteriovenous fistulas (AVFs) were classified into four types based on the vascular supply, vascular drainage, and nidus location according to the

Received July 23, 2020; Accepted October 21, 2020

Copyright $\odot 2021$ by The Japan Neurosurgical Society This work is licensed under a Creative Commons AttributionNonCommercial-NoDerivatives International License. traditional classification system. ${ }^{1-4)}$ Dural AVFs are most common forms of spinal AVMs and extradural AVF accounts for approximately $1.6 \%$ of all spinal $\mathrm{AVMs}^{5)}$ The classification of spinal extradural AVFs was reported based on the case series treated by microsurgery in 2009 and endovascular interventions in 2011 ${ }^{6-9)}$ Moreover, the review and treatment strategy of spinal extradural AVFs according to the venous drainage patterns were reported. ${ }^{7,8)}$ RangelCastilla et al. classified that extradural AVFs have two distinct subtypes: extradural AVFs with intradural venous drainage (type A) and extradural AVFs 
with pure extradural drainage only (type B). The type B extradural AVF in the cervical spine is rare among extradural AVFs and over a dozen cases were reported in the literature ${ }^{6-22)}$ and almost cases were treated with transarterial approach. Takai et al. proposed that the goal of the treatment is the mass reduction of the venous plexus in patients with extradural AVFs without intradural venous drainage which was classified as type B. Because, the cause of compressive myelopathy is considered due to the compression from the enlarged extradural vertebral venous plexus. ${ }^{12)}$ Endovascular embolization of the feeding arteries was performed as the first-choice treatment to block arterial reflux into the extradural venous plexus. $66.7 \%$ (2/3 cases) could complete or nearly complete embolization with transarterial embolization. ${ }^{12)}$ Here, we report a case of a cervical spinal extradural AVFs without intradural venous drainage, which was successfully treated with the combination of transvenous and supplementary transarterial embolization.

\section{Case Report}

A 59 year-old man, who had a past history of myasthenia gravis, presented to our hospital. He had no traumatic episode and no prior cervical spine surgery. He had been aware of bilateral upper limbs pain, skillful movement disorders, and gait disturbance from approximately 5 months before and the symptoms had gradually progressed.
Cervical X-ray showed a dilation of the right foramen at C3/4 and no instability. On magnetic resonance imaging (MRI), an epidural mass was recognized located around the right foramen of the $\mathrm{C} 2-\mathrm{C} 4$ compressing the spinal cord to the left (Fig. 1a-1c).

The mass was consisted with low signal intensity both on $\mathrm{T} 1$ and $\mathrm{T} 2$ suggesting a flow void of a vascular lesion. A part of the mass lesion was enhanced using contrast enhancement (Fig. 1d). 3D-computed tomography angiography indicated extradural AVFs on the right in the cervical spine with multi-feeders (Fig. 1e).

Angiogram indicated multi-shunting points at the epidural space of right foramens of $\mathrm{C} 2 / 3$ and C3/4. The right subclavian artery angiogram demonstrated a high flow arteriovenous shunts at the extradural space around the right foramen of C3/4 from multibranches of the ascending cervical artery (ACA) which consisted the main portion of the AVF (Fig. 2a). Right vertebral artery (VA) angiogram demonstrated arteriovenous shunts at the extradural space around the right foramen of $\mathrm{C} 3 / 4$ from radicular artery of V1 portion (Fig. 2b). Left VA angiogram demonstrated arteriovenous shunts at the extradural space around the right foramen of $\mathrm{C} 2 / 3$ and $\mathrm{C} 3 / 4$ from radicular artery of $\mathrm{V} 1$ portion (Fig. 2c). The flow was drained to the extradural vertebral venous plexus without intradural and intracranial drainage. Cone beam CT images more clearly suggested that it was extradural AVF (Fig. 3). Based on the above
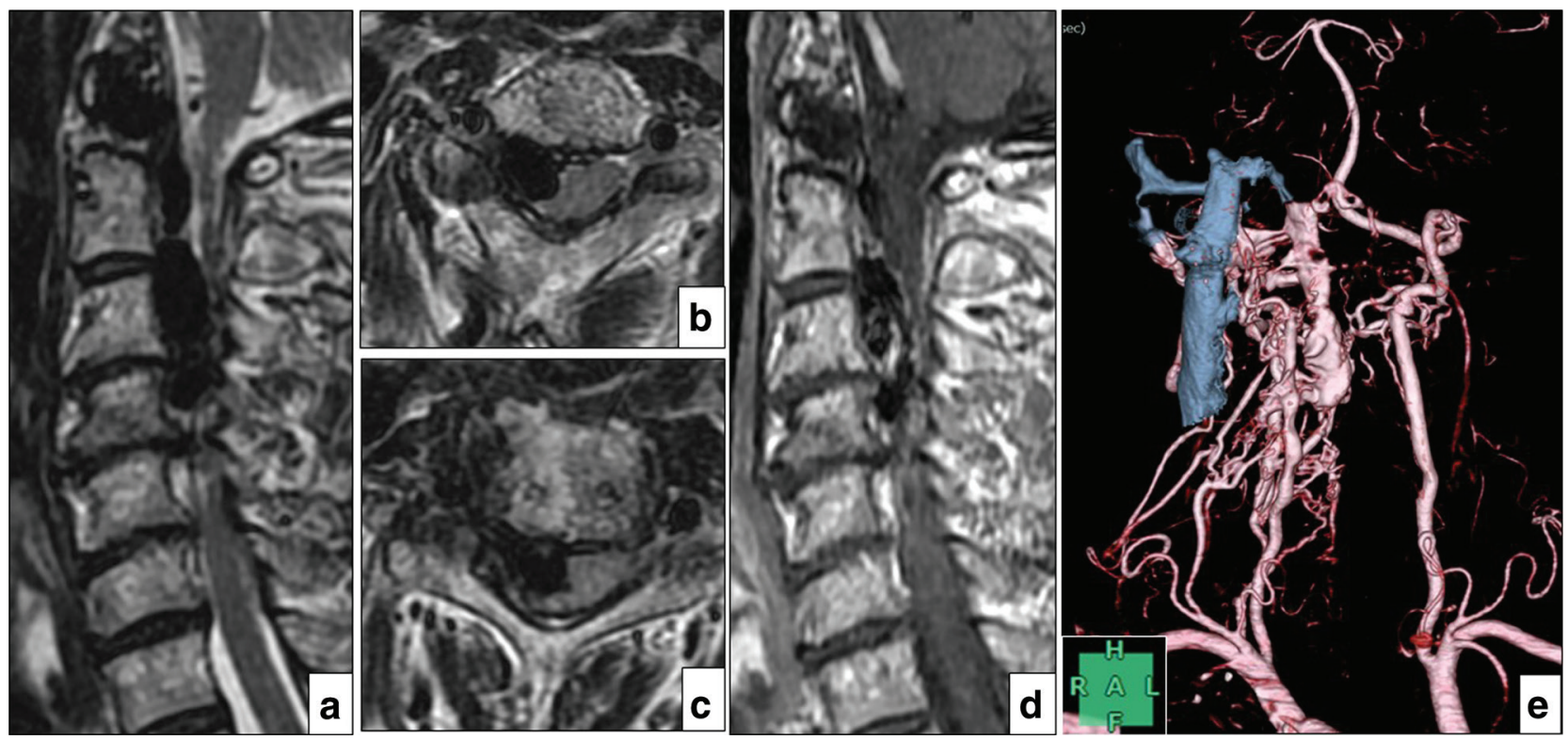

Fig. 1 Preoperative MR images and CTA image. (a) T2 on sagittal view, (b) T2 on axial at C2/3, (c) T2 on axial at C3/4, (d) Gd-enhanced T1 on sagittal view, and (e) 3D construction image (red: artery, blue: vein). CTA: computed tomographic angiography, Gd: gadolinium, MR: magnetic resonance, 3D: three-dimensional. 



Fig. 2 Angiogram. (a) Right subclavian angiogram, (b) right VA angiogram, and (c) left VA angiogram.

findings, it was diagnosed as extradural AVF classified as type B1 by Rangel-Castilla L.

Endovascular treatment was performed under general anesthesia and systemic heparinization to maintain the activated clotting time at level above twofold to threefold of the baseline value. First, transvenous embolization was conducted. First, 6 French intermediate catheter assembled with 8 French guiding catheter system was placed in the right internal jugular vein via right femoral vein. The microcatheter (Excelsior 1018; Stryker, Fremont, CA, USA) was coaxially inserted into extradural space at C3/4 on the right side nearby the shunting point via anterior condylar emissary vein in the hypoglossal canal and coil embolization was performed (Fig. 4). After this procedure, most of the shunt volume decreased. Second, 5 French guiding catheter (Envoy; Cordis, Miami Lakes, FL, USA) was placed in the left VA via left femoral artery. The microcatheter (Excelsior SL-10; Stryker, Fremont, CA, USA) was coaxially inserted into the radicular artery at left V1 portion and coil embolization was done. Third, the same 5 French guiding catheter was repositioned in the origin of right ACA and the branches of right ACA embolized with n-butyl cyanoacrylate (NBCA; 33\% concentration) to prevent the recurrence form the collateral branches. The combination of transvenous and transarterial embolization leaded complete arteriovenous shunts obliteration (Fig. 5). The systemic heparinization was naturally reversed because the AVF was not related to the intraspinal venous reflux. The myelopathy gradually recovered and the follow up angiogram 2 weeks later demonstrated complete shunt obliteration.

\section{Discussion}

Spinal dural AVFs commonly cause the progressive myelopathy because the arterial blood reflux into the intradural veins increase medullary venous pressure. ${ }^{23)}$ On the other hand, spinal extradural AVFs cause myelopathy or radiculopathy because abnormal direct connection between arteries and the extradural venous plexus within spinal canal causes venous hypertension, mechanical compression, 

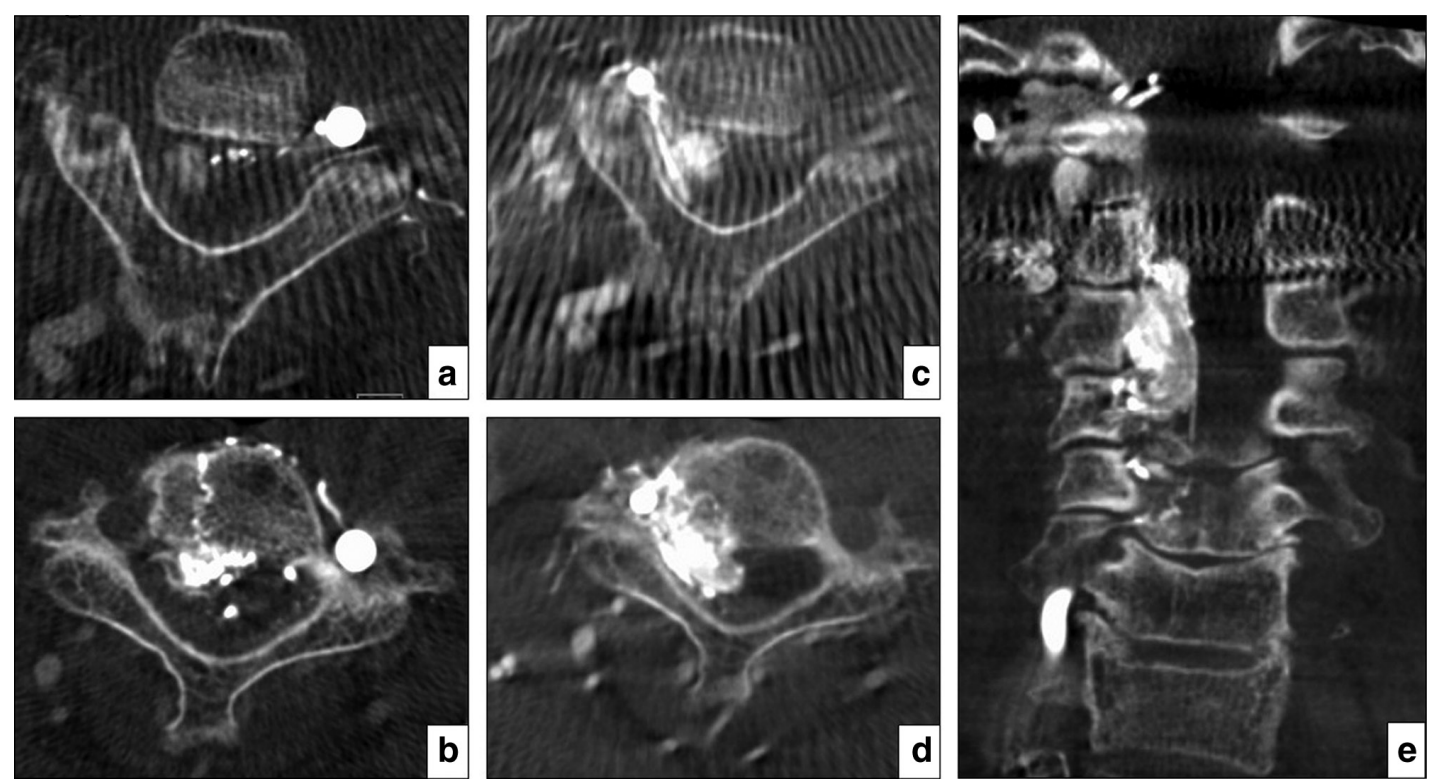

Fig. 3 Cone beam CT image with right and left VA angiogram showed the direct reflux to extradural vertebral venous plexus. (a) Axial image with right VA angiogram at C2 level, (b) axial image with left VA angiogram at C3 level, (c) axial image with right VA angiogram at C2 level, (d) axial image with right VA angiogram at C3 level, and (e) coronal image with right VA angiogram. CT: computed tomography, VA: vertebral artery.

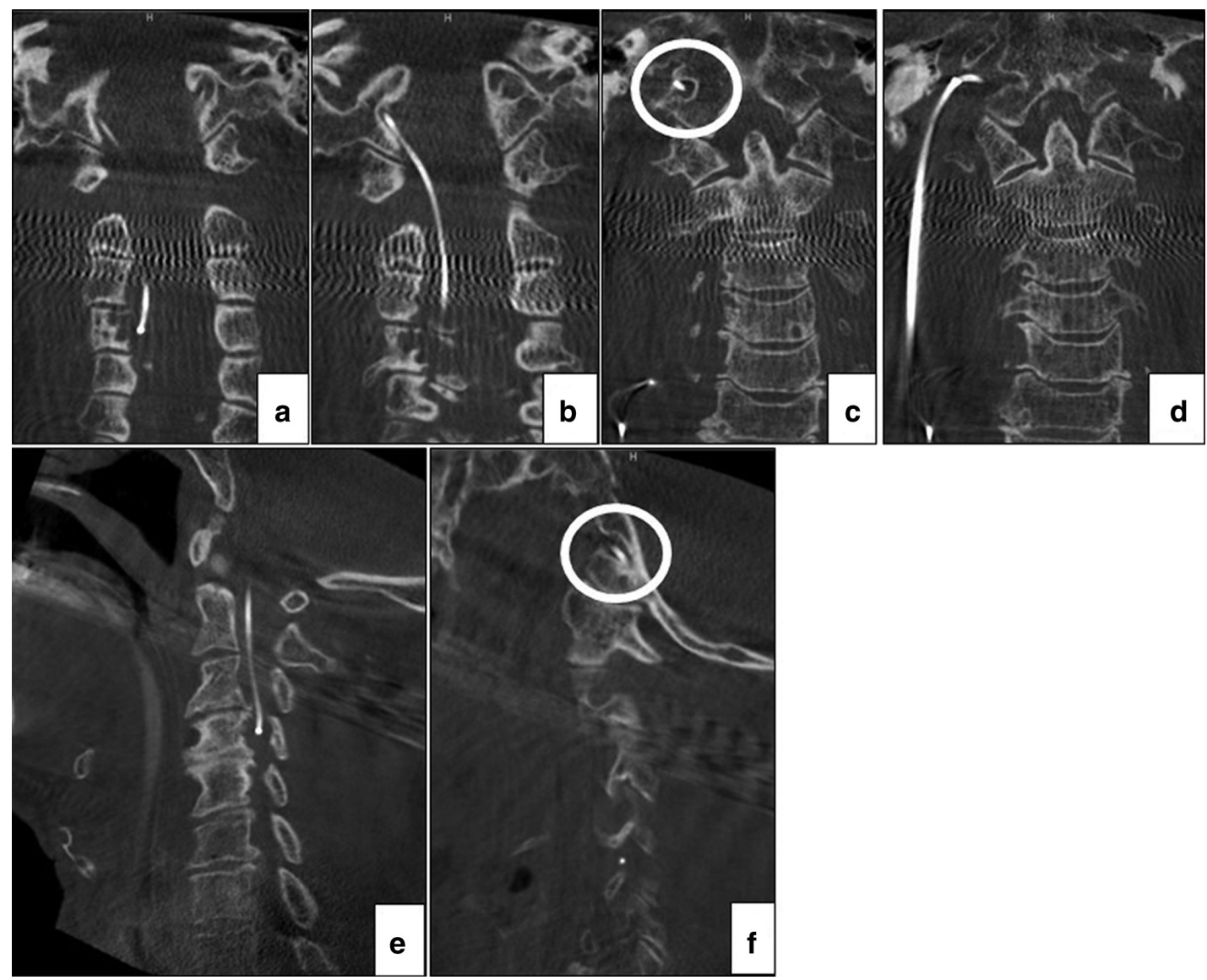

Fig. 4 Cone beam CT image demonstrated that the microcatheter was inserted into extradural space at C4 body level via hypoglossal canal. White ring: hypoglossal canal. (a-d) Coronal image, (e, f) sagittal image. CT: computed tomography. 

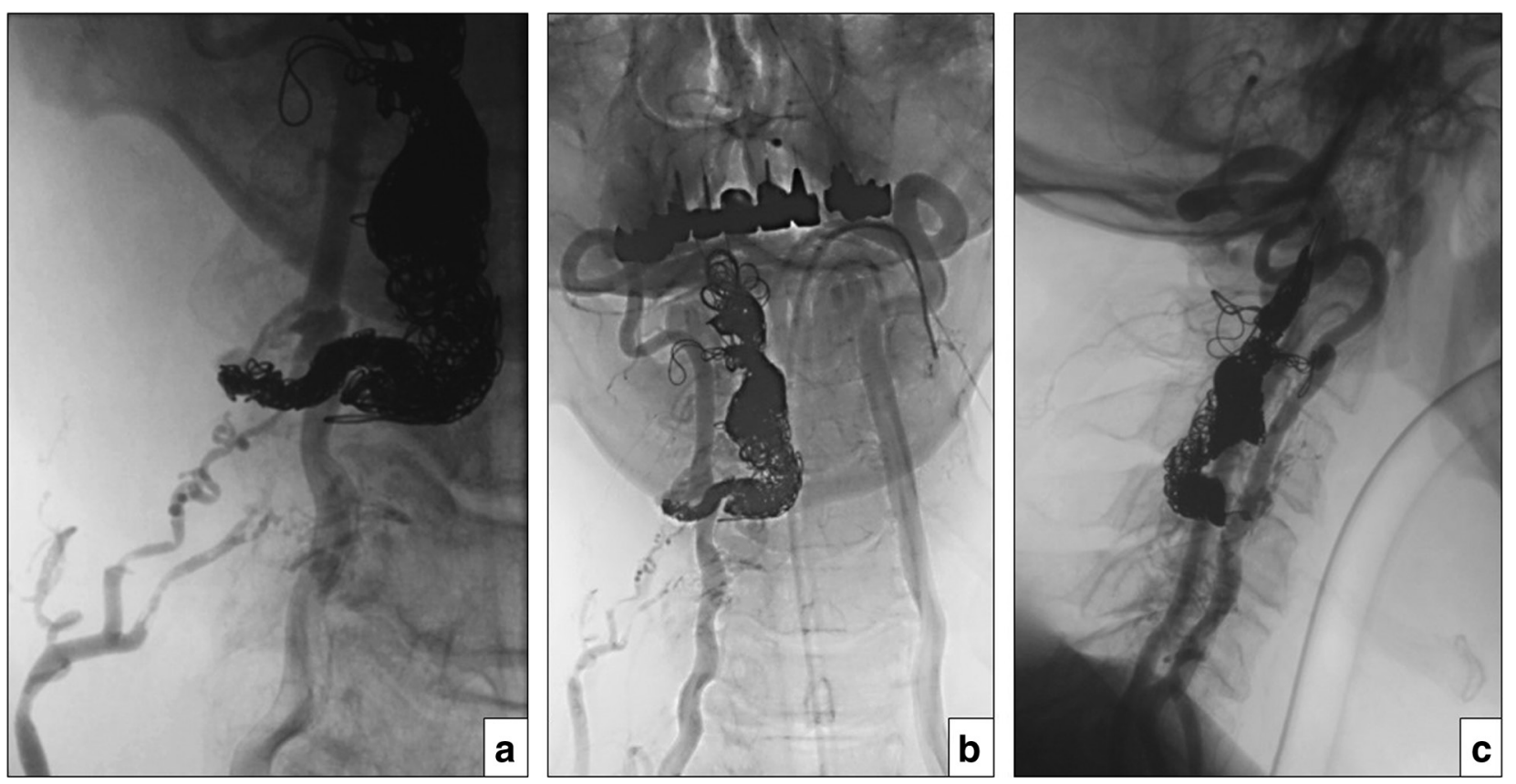

Fig. 5 Final angiogram. (a) Right subclavian angiogram. Arteriovenous shunts were obliterated. (b, c) Bilateral VA angiogram at the same time. Arteriovenous shunts were obliterated. VA: vertebral artery.

and vascular steal effect. ${ }^{6,8,18,24-26)}$ Extradural AVFs rarely causes hemorrhage. ${ }^{18)}$

Kiyosue et al. ${ }^{27}$ reviewed angiographic and clinical characteristics of epidural and dural AVFS in the thoracolumbar spine. In the review of epidural AVFs in 59 and dural AVFs in 108, epidural AVFs and dural AVFs showed similar symptoms and male predominance. There were no significant differences in age, sex, or symptoms. A history of spinal surgery or trauma was less frequently observed in the dural AVF (12\%) than epidural AVFs (36\%). Huang et al. ${ }^{8)}$ reviewed spinal extradural AVFs in 2013. In this review, 54 cases in cervical spine were summarized. As a pertinent history, neurofibromatosis type 1 of NF1, prior spinal surgery, and prior spinal trauma were $16 / 54(30 \%), 5 / 54(9 \%)$, and $7 / 54(13 \%)$, respectively. 50/54 (92\%) showed extradural drainage only. This review was excellent study but contained many old reports and it is unclear whether its exact diagnosis of extradural AVF was correct.

In 2011, Rangel-Castilla et al. ${ }^{7)}$ classified that extradural AVFs have two distinct subtypes: extradural AVFs with intradural venous drainage (type A) and extradural AVFs with pure extradural drainage only (type B). In 2012, Takai et al. ${ }^{28)}$ analyzed and reviewed the spinal extradural AVFs with or without intradural venous drainage published between 1990 and 2011. In the review, posttraumatic and postoperative extradural AVFs were excluded because the spinal extradural AVF is defined as a spontaneous abnormal direct connection between an artery or arteries and the extradural venous plexus. According to the reviews, spinal extradural AVFS with intradural venous drainage (type A) are diagnosed in patients around the 6th decade of life and causes myelopathy due to venous congestion, which is similar to dural AVFs. On the other hand, spinal extradural AVFs without intradural venous drainage (type B) are diagnosed in patients around the 3rd decade of life and had a tendency to show a normal signal intensity of the cord with a severe mass effect due to an enlarged extradural venous plexus; they commonly occurred in the cervical and upper thoracic regions $(18 / 22,82 \%)$. Therefore, type B extradural AVFs present with compressive myelopathy or radiculopathy due to the compression of the thecal sac or root sleeves by the enlarged extradural venous plexus. We summarized the extradural AVFs without venous drainage (type B) in the cervical spine by adding the cases reported after 2012 (Table 1). In almost cases, transarterial approach is chosen for spinal extradural AVFs. In Huang W's review, 65 cases of extradural AVFs in whole spine among 101 cases underwent endovascular approach and the approach was transarterial in $87 \%$ of cases, transvenous in $11 \%$, and a combination in $2 \%{ }^{8)}$ Embolization materials included NBCA in $34 \%$ of cases, coils in $34 \%$, balloons in $23 \%$, and Onyx in $17 \%$. Takai et al. ${ }^{12)}$ reported that $66.7 \%$ (2/3 cases) could complete or nearly complete embolization 
Table 1 Summary of clinical characteristics in patients with type B spinal extradural AVFs

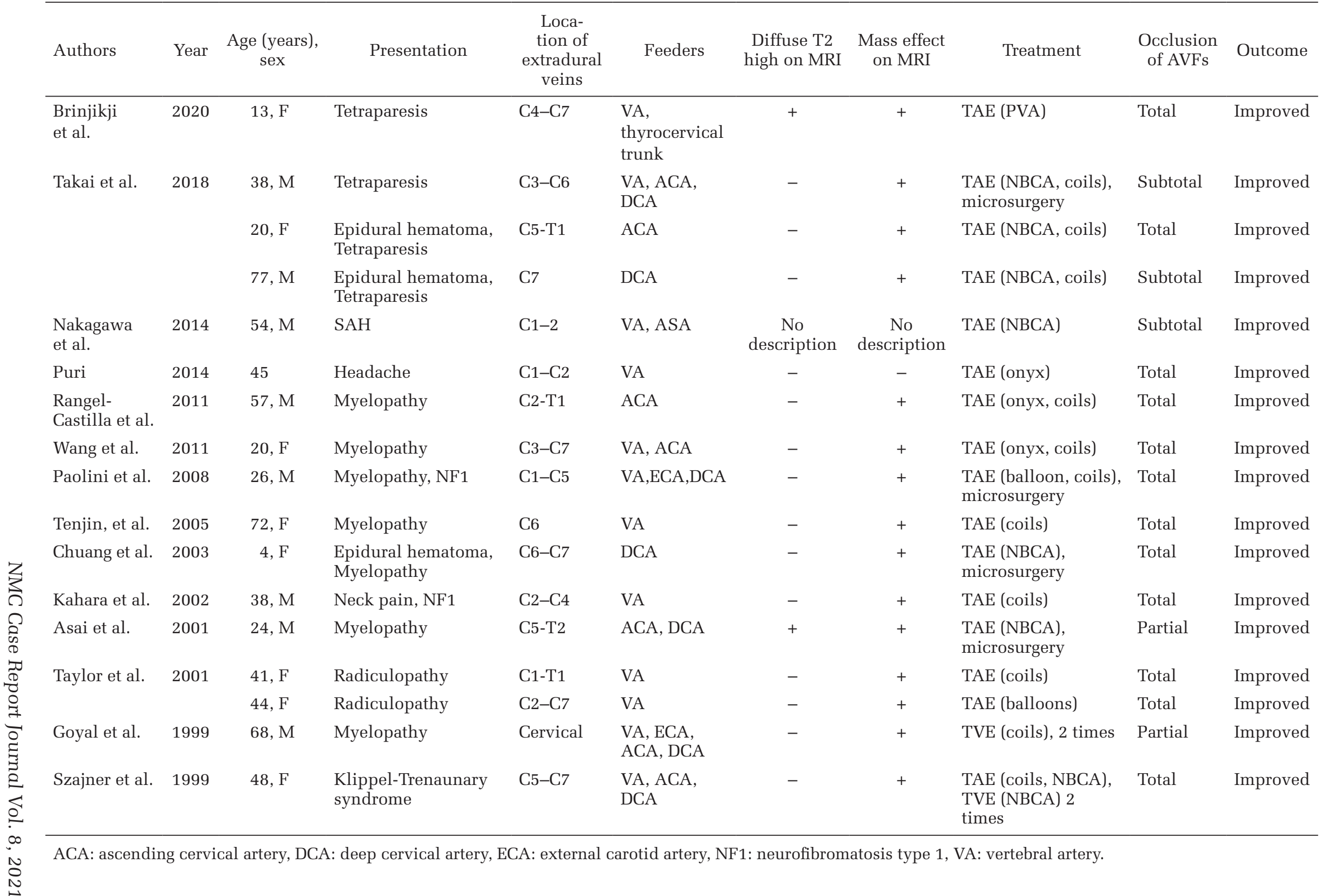


with transarterial embolization. In the lumbar spine, Kiyosue et al. ${ }^{29)}$ reported and classified the ventral epidural AVFs regarding the draining routes; the perimedullary venous drainage type (PM type), the paravertebral venous drainage type (PV type), and the combined perimedullary and paravertebral venous drainage type (PMPV type). ${ }^{29)}$ The type B extradural AVF in the cervical spine defined by Rangel-Castilla et al. was considered to correspond to the PV type by Kiyosue et al. and our case was also diagnosed as this type.

In our case, we tried transarterial embolization of the main feeders from ACA, but we judged that it was dangerous because the shunts were high flow and the NBCA and coils might flow over the shunting points into the jugular vein. Moreover, the coil embolization might result in only feeder occlusion and recurrence of the epidural AVFs because it could not obliterate the draining vein over multi-shunting points. Therefore, transvenous approach was performed as a first choice. Anterior condylar emissary vein in the hypoglossal canal from right jugular vein was chosen as the route to the enlarged cervical extradural venous plexus. Arteriovenous shunts from multi-branches of ACA almost disappeared. Next, transarterial embolization with coil and NBCA leaded complete obliteration of the AVFs. Theoretically, coil embolization into the venous plexus might be avoided because the coils may remain as a mass and may compress the dural sac and the root sleeve. However, the foramen at C3/4 on right was enlarged and the discontinuation of the arterial pulsation might improve myelopathy.

In this case, we did not choose microsurgical resection because the arteriovenous shunts supplied from bilateral VA and had multi-shunting points and was located at the ventral side. It would be very difficult to resect multi-feeders from bilateral VA and multi-shunts to control and stop bleeding even if complete removal of the facet joints was done with anterior or posterior approach.

\section{Conclusion}

Extradural AVF of the cervical spine is a rare disease and its treatment strategy should be discussed carefully. When it is an extradural AVFs without intradural venous drainage and cause compressive myelopathy due to an enlarged vertebral venous plexus, flow reduction is necessary. Transvenous approach via anterior condylar emissary vein in the hypoglossal canal might be one option when the arteriovenous shunts in the upper cervical spine has a high flow shunt.

\section{Conflicts of Interest Disclosure}

No potential conflicts of interest were disclosed.

\section{References}

1) Kim LJ, Spetzler RF: Classification and surgical management of spinal arteriovenous lesions: arteriovenous fistulae and arteriovenous malformations. Neurosurgery 59: S195-201; discussion S193-113, 2006

2) Mourier KL, Gobin YP, George B, Lot G, Merland JJ: Intradural perimedullary arteriovenous fistulae: results of surgical and endovascular treatment in a series of 35 cases. Neurosurgery 32: 885-891; discussion 891, 1993

3) Oldfield EH, Doppman JL: Spinal arteriovenous malformations. Clin Neurosurg 34: 161-183, 1988

4) Takai K, Kin T, Oyama H, et al.: The use of $3 \mathrm{D}$ computer graphics in the diagnosis and treatment of spinal vascular malformations. J Neurosurg Spine 15: 654-659, 2011

5) Bao YH, Ling F: Classification and therapeutic modalities of spinal vascular malformations in 80 patients. Neurosurgery 40: 75-81, 1997

6) Clarke MJ, Patrick TA, White JB, et al.: Spinal extradural arteriovenous malformations with parenchymal drainage: venous drainage variability and implications in clinical manifestations. Neurosurg Focus 26: E5, 2009

7) Rangel-Castilla L, Holman PJ, Krishna C, Trask TW, Klucznik RP, Diaz OM: Spinal extradural arteriovenous fistulas: a clinical and radiological description of different types and their novel treatment with Onyx. J Neurosurg Spine 15: 541-549, 2011

8) Huang W, Gross BA, Du R: Spinal extradural arteriovenous fistulas: clinical article. J Neurosurg Spine 19: 582-590, 2013

9) Asai J, Hayashi T, Fujimoto T, Suzuki R: Exclusively epidural arteriovenous fistula in the cervical spine with spinal cord symptoms: case report. Neurosurgery 48: 1372-1375; discussion 1375-1376, 2001

10) Kawabori M, Hida K, Yano S, Asano T, Iwasaki Y: Cervical epidural arteriovenous fistula with radiculopathy mimicking cervical spondylosis. Neurol Med Chir (Tokyo) 49: 108-113, 2009

11) Brinjikji W, Colombo E, Lanzino G: Clinical and angioarchitectural characteristics of spinal vascular malformations of the cervical spine. J Neurosurg Spine 32: 755-762, 2020

12) Takai K, Shojima M, Imai H, Saito N, Taniguchi M: Microsurgical and endovascular treatments of spinal extradural arteriovenous fistulas with or without intradural venous drainage. World Neurosurg 111: e819-e829, 2018

13) Nakagawa I, Park HS, Hironaka Y, Wada T, Kichikawa K, Nakase H: Cervical spinal epidural arteriovenous fistula with coexisting spinal anterior spinal artery aneurysm presenting as subarachnoid 
hemorrhage--case report. J Stroke Cerebrovasc Dis 23: e461-e465, 2014

14) Puri AS, Telischak NA, Vissapragada R, Thomas AJ: Analysis of venous drainage in three patients with extradural spinal arteriovenous fistulae at the craniovertebral junction with potentially benign implication. J Neurointerv Surg 6: 150-155, 2014

15) Wang Q, Song D, Chen G: Endovascular treatment of high-flow cervical direct vertebro-vertebral arteriovenous fistula with detachable coils and Onyx liquid embolic agent. Acta Neurochir (Wien) 153: 347-352, 2011

16) Paolini S, Colonnese C, Galasso V, et al.: Extradural arteriovenous fistulas involving the vertebral artery in neurofibromatosis Type 1. J Neurosurg Spine 8: 181-185, 2008

17) Tenjin H, Kimura S, Sugawa N: Coil embolization of vertebro-vertebral arteriovenous fistula: a case report. Surg Neurol 63: 80-83, discussion 83, 2005

18) Chuang NA, Shroff MM, Willinsky RA, Drake JM, Dirks PB, Armstrong DC: Slow-flow spinal epidural AVF with venous ectasias: two pediatric case reports. AJNR Am J Neuroradiol 24: 1901-1905, 2003

19) Kahara V, Lehto U, Ryymin P, Helen P: Vertebral epidural arteriovenous fistula and radicular pain in neurofibromatosis type I. Acta Neurochir (Wien) 144: 493-496, 2002

20) Taylor CG, Husami Y, Colquhoun IR, Byrne JV: Direct cervical vertebro-venous fistula with radiculopathy and MRI changes resolving after successful endovascular embolisation: a report of two cases. Neuroradiology 43: 1118-1122, 2001

21) Goyal M, Willinsky R, Montanera W, terBrugge K: Paravertebral arteriovenous malformations with epidural drainage: clinical spectrum, imaging features, and results of treatment. AJNR Am J Neuroradiol 20: 749-755, 1999

22) Szajner M, Weill A, Piotin M, Moret J: Endovascular treatment of a cervical paraspinal arteriovenous malformation via arterial and venous approaches. AJNR Am J Neuroradiol 20: 1097-1099, 1999

23) Jellema K, Tijssen CC, van Gijn J: Spinal dural arteriovenous fistulas: a congestive myelopathy that initially mimics a peripheral nerve disorder. Brain 129: 3150-3164, 2006

24) Arnaud O, Bille F, Pouget J, Serratrice G, Salamon G: Epidural arteriovenous fistula with perimedullary venous drainage: case report. Neuroradiology 36: 490-491, 1994

25) Chul Suh D, Gon Choi C, Bo Sung K, Kim KK, Chul Rhim S: Spinal osseous epidural arteriovenous fistula with multiple small arterial feeders converging to a round fistular nidus as a target of venous approach. AJNR Am J Neuroradiol 25: 69-73, 2004

26) Alexander MJ, Grossi PM, Spetzler RF, McDougall CG: Extradural thoracic arteriovenous malformation in a patient with Klippel-Trenaunay-Weber syndrome: case report. Neurosurgery 51: 1275-1278; discussion 1278-1279, 2002

27) Kiyosue H, Matsumaru Y, Niimi Y, et al.: Angiographic and clinical characteristics of thoracolumbar spinal epidural and dural arteriovenous fistulas. Stroke 48: 3215-3222, 2017

28) Takai K, Taniguchi M: Comparative analysis of spinal extradural arteriovenous fistulas with or without intradural venous drainage: a systematic literature review. Neurosurg Focus 32: E8, 2012

29) Kiyosue H, Tanoue S, Okahara M, Hori Y, Kashiwagi J, Mori H: Spinal ventral epidural arteriovenous fistulas of the lumbar spine: angioarchitecture and endovascular treatment. Neuroradiology 55: 327-336, 2013

Corresponding author: Toshiyuki Okazaki, MD, PhD Center for Minimally Invasive Spinal Surgery, Shinyurigaoka General Hospital, 255 Furusawa, Asao-ku, Kawasaki, Kanagawa 215-0026, Japan. e-mail: tokazaki007@gmail.com 